INDIGO (EU-India multilateral research calls). Authors acknowledge EC of INNO-INDIGO for the funds.

Disclosure of Interests: None declared

DOI: 10.1136/annrheumdis-2019-eular.7609

\section{FRI0512 RETRO-INVERSO TAT-BECLIN-1 INDUCES SYNOVIAL FIBROSIS AND DOES NOT PROTECT CARTILAGE FROM DEGENERATION IN A MOUSE MODEL OF OA}

Jason Rockel, Brian Wu, Sayaka Nakamura, Evgeny Rossomacha, Mohit Kapoor. University Health Network, Toronto, Canada

Background: Beclin-1 is a component of the autophagy pathway necessary for formation of autophagosomes, contributing to autophagy-mediated cellular homeostasis. Enhancing autophagy through inhibition of mTOR activity, either via genetic deletion in chondrocytes or intra-articular injection of rapamycin, attenuates progression of surgically-induced models of osteoarthritis (OA). Retro-inverso TAT-Beclin-1 is a cell-permeable peptide which competes for binding to the endogenous Beclin-1 inhibitor GAPR-1, thus promoting autophagy. It is unknown whether activation of Beclin-1 is sufficient to protect joints from osteoarthritis progression.

Objectives: For this study, we sought to determine if retro-inverso TATBeclin-1 could attenuate $\mathrm{OA}$ progression in a surgically-induced mouse model.

Methods: Eight-week old C57BL/6 mice underwent destabilization of the medial meniscus (DMM) surgery to induce $\mathrm{OA}$, or sham surgery as a control. Mice were injected intra-articularly with retro-inverso TAT-Beclin-1 ( $2 \mathrm{mg} / \mathrm{kg}$ in $5 \mu \mathrm{l}$ ) twice weekly for 2 or 9 weeks. Mice were sacrificed at 10 -weeks post-surgery. Knee joints were stained with Safranin-O/Fastgreen to evaluate cartilage degeneration and Masson's trichrome to determine degree of synovitis using OARSI scoring for mice. Sections were stained for $\alpha$-SMA (myofibroblast) and CD45 (hematopoietic-origin cell) to evaluate changes in markers of fibrosis and inflammation, respectively. Results: As opposed to the effects of mTOR deletion in cartilage or rapamycin treatment in joints, injection of retro-inverso TAT-Beclin-1 for 2 into knee joints of mice with DMM-induced OA had no effect on the degree of articular cartilage degeneration in the tibia or femur as compared to PBS-injected controls. However, in both sham and DMM mice, retro-inverso TAT-Beclin-1 for 2 or 9 weeks of treatment induced a pronounced thickening of the synovium with increased cell numbers and collagen deposition compared to PBS-treated mice. The increased number of synovial cells in 9-week treated mice did not show substantial expression of $\alpha-S M A+$ or CD45+ cells, suggesting the increased number of cells and matrix in the synovium was independent of myofibroblast differentiation or inflammatory influx.

Conclusion: Contradictory to our expected results, retro-inverso TATBeclin-1 did not attenuate cartilage degeneration. Rather, it promoted substantial synovial thickening that likely involved cell proliferation and collagen deposition. This severe fibrotic phenotype appears independent of myofibroblast differentiation or inflammation, normally associated with typical fibrotic responses. To evaluate the potential for dose responses with retro-inverso TAT-Beclin-1 in synovial joints, we are currently modifying our dosing strategy in an effort to determine possible disease modifying effects of this novel Beclin-1 activator.

Disclosure of Interests: None declared

DOI: 10.1136/annrheumdis-2019-eular.2680

\section{FRI0513 HISTONE-ACETYLTRANSFERASES CBP AND P300 REGULATE AUTOPHAGY AND PROTEASOMAL DEGRADATION IN SYNOVIAL FIBROBLASTS}

Monika Krosel $^{1,2}$, Marcel Gabathuler ${ }^{1}$, Christoph Kolling ${ }^{3}$, Matija Tomsic ${ }^{2}$, Oliver Distler ${ }^{1}$, Caroline Ospelt ${ }^{1}$, Kerstin Klein ${ }^{1} .{ }^{1}$ Center of Experimental Rheumatology, Department of Rheumatology, University Hospital Zurich, Zurich, Switzerland; ${ }^{2}$ University Medical Centre Ljubljana, Department of Rheumatology, Ljubljana, Slovenia; ${ }^{3}$ Schulthess Clinic, Zurich, Switzerland

Background: Proteasomal degradation and autophagy are the major catabolic pathways that maintain the homeostasis of cells and are associated with cell survival. The histone acetyltransferases cAMP-response element binding protein binding protein (CBP) and p300 are close homologues and widely accepted as redundant proteins.

Objectives: To analyse individual functions of CBP and p300 in catabolic pathways in rheumatoid arthritis (RA) synovial fibroblasts (SF).

Methods: SF were isolated from knee, shoulder and hand joints of RA patients undergoing joint replacement surgery. The expression of CBP and p300 was silenced by transfection of antisense LNA gapmeRs (12,5 nM). 24h after transfection cells were stimulated with TNF- $\alpha$ (10 ng/ml, 24h). Transcriptomes were determined by RNA-seq (Illumina NovaSeq 6000, $n=6$ ). Pathway enrichment analysis of RNA-seq data (fold change $>1.5$, FDR $<0.05$ ) was performed using DAVID bioinformatic resources. Autophagy was assessed by Western blotting using LC3B conversion and p62 as autophagy markers $(n=4)$ in presence and absence of bafilomycin A1 (100 nM, 4h), a lysosomal inhibitor. Cell death was analysed using the CytoTox-Glo cytotoxicity assay.

Results: The top pathway identified after silencing of p300 in SF in presence $\left(p=1.33 \times 10^{-10}\right)$ and absence of TNF- $\alpha \quad\left(p=1.76 \times 10^{-10}\right)$ was 'proteasome', with an enrichment of genes contributing to 'proteasome assembly' and 'proteasome regulation'. The expression of several genes encoding proteasome subunits was increased after p300 silencing but unaffected by silencing of CBP. Genes contributing to the biological processes 'autophagy' $(p<0.05)$ and 'regulation of autophagy' $(p<0.05)$ were enriched afte silencing of CBP and p300, whereas 'autophagy assembly' was only affected by CBP silencing. In RNA-seq data, the expression of MAP1LC3B, encoding the autophagy marker LC3B, and the autophagy substrate p62, was increased by $\mathrm{p} 300$ silencing but slightly decreased by CBP silencing. In line with the RNA expression, silencing of CBP reduced the conversion of $\mathrm{LC} 3 \mathrm{~B}$ and the protein expression of $\mathrm{p} 62$ in presence and absence of TNF- $\alpha$. Results were similar in presence of bafilomycin A1, indicating a decrease in autophagosome synthesis. In contrast, the conversion of LC3B and p62 expression were increased after silencing of p300 in unstimulated SF, indicating increased autophagy. This effect was lost for LC3B after treatment with TNF- $\alpha$, and LC3B conversion was even decreased in presence of bafilomycin A1. This indicates a late stage block of autophagy after silencing of p300 in TNF- $\alpha$-stimulated SF. In line with this, silencing of p300 in SF $(n=6, p<0.05)$ increased cell death only in presence of TNF- $\alpha$. Viability of SF was not affected by silencing of CBP. Conclusion: Here we identified $\mathrm{p} 300$ as a major regulator of the proteasome in SF and provide first evidence for individual functions of CBP and p300 in regulating autophagy in SF.

Disclosure of Interests: Monika Krosel: None declared, Marcel Gabathuler: None declared, Christoph Kolling: None declared, Matija Tomsic: None declared, Oliver Distler Grant/research support from: Prof. Distler received research funding from Actelion, Bayer, Boehringer Ingelheim and Mitsubishi Tanabe to investigate potential treatments of scleroderma and its complications, Consultant for: Prof. Distler has/had consultancy relationship within the last 3 years with Actelion, AnaMar, Bayer, Boehringer Ingelheim, ChemomAb, espeRare foundation, Genentech/Roche, GSK, Inventiva, Italfarmaco, iQvia, Lilly, medac, Medlmmune, Mitsubishi Tanabe Pharma, Pharmacyclics, Novartis, Pfizer, Sanofi, Serodapharm and UCB in the area of potential treatments of scleroderma and its complications. In addition, he had/has consultancy relationship within the last 3 years with A. Menarini, Amgen, Abbvie, GSK Mepha, MSD, Pfizer and UCB in the field of arthritides and related disorders, Caroline Ospelt: None declared, Kerstin Klein: None declared DOI: 10.1136/annrheumdis-2019-eular.5605

\section{FRI0514 \\ NEW DIAGNOSTIC BIOMARKER OF BONE TISSUE METABOLISM DISORDERS IN RHEUMATOID ARTHRITIS}

L Seewordova $^{1}$, J Polyakova ${ }^{1}$, B Zavodovsky ${ }^{1,2}$, Eugene Papichev ${ }^{1}$,

Akhverdyan Yury ${ }^{1} .{ }^{1} 1$ Treatment and Prevention of Joint Disease Laboratory/ Federal State Budgetary Institution «Zborovsky Research Institute of Clinical and Experimental Rheumatology", Volgograd, Russian Federation; ${ }^{2} 2$ Volgograd State Medical University, Volgograd, Russian Federation

Background: Bone mineral density and proteins/peptides determination in blood and urine as markers of bone resorption and formation are cur rently used to diagnose osteoporosis (OP) and metabolic bone diseases However, these methods have some disadvantages for bone turnover evaluation. Recent evidence suggests that in RA changes in the secre tion of hormones of white adipose tissue can be revealed $[1,2,3,4]$. One of them is Adiponectin possessing anti-inflammatory, anti-diabetic and antiatherogenic properties. Changes in Adiponectin levels may reflect influence of immune inflammation on bone turnover.

Objectives: To study the clinical and diagnostic value of serum Adiponectin determination in RA patients complicated by OP.

Methods: We examined 88 women with documented diagnosis of RA and mean disease duration of $6.56 \pm 0.88$ years. We used EULAR/ARA 2010 criteria to diagnose the patients. Female patients with II degree of disease activity (DAS28), Steinbrocker stage II (erosive), rheumatoid factor- and anti-cyclic-citrullinated peptide antibody-positive were prevalent We excluded patients who had surgery or developed an infection within the last 8 weeks, pregnant and breast-feeding women, those with severe heart, liver or kidney disease, immune deficiency, leukopenia or chronic infection. A control group of 45 healthy females aged of 25 and 59 years were included in the study. There were no reported findings of 
joint pain and RA symptoms in the group. The groups were adjusted for age $(p>0.05)$ and showed no statistically significant differences.

We measured serum Adiponectin levels $(\mu \mathrm{g} / \mathrm{ml})$ using Human Adiponectin ELISA commercial test systems (BioVendor, Czech Republic, cat № RD195023100). We used spectrophotometer with wavelength of $450 \mathrm{~nm}$ to detect the test results («Multiskan» immunoenzyme analyzer, Finland). We plotted a curve using computer software. We diagnosed OP using dual-energy X-ray absorptiometry with LUNAR DPX PRO (GE, USA).

Results: Serum adiponectin levels in the control group were $12.5 \pm 0.9 \mu \mathrm{g} /$ $\mathrm{ml}(\mathrm{M} \pm \mathrm{m})$. Adiponectin levels in healthy subjects measured as $\mathrm{M} \pm 2 \delta$, ranged between 0.44 and $24.56 \mu \mathrm{g} / \mathrm{ml}$. Patients with OP and RA had significantly higher levels of serum Adiponectin $(p<0.001)$. Mean serum Adiponectin levels in RA patients who had normal bone density and had no OP were $35.21 \pm 0.6 \mu \mathrm{g} / \mathrm{ml}$. Mean serum Adiponectin levels in RA/OP patients with low bone mineral density were $52.42 \pm 0.69 \mu \mathrm{g} / \mathrm{ml}$. Adiponectin levels of $44 \mu \mathrm{g} / \mathrm{ml}$ and higher were associated with osteoporosis. Adiponectin levels of $43.9 \mu \mathrm{g} / \mathrm{ml}$ and lower were associated with normal bone density.

Conclusion: Thus, we revealed that Adiponectin levels depend on osteoporosis presence in RA patients. We suppose that Adiponectin determination may be useful laboratory marker for OP diagnosis. The test may be used to reduce the risk of low-energy fractures and to improve the quality of life in RA.

\section{REFERENCES:}

[1] Akhverdyan $Y$. et al. Laboratory markers of inflammation and serum nicotinamide phosphoribosyltransferase level in rheumatoid arthritis patients// Ann. Rheum. Dis., 2017, vol.76, suppl.2, p.1149.

[2] Kvlividze Z. et al. Elevated nesfatin-1 levels in patients with rheumatoid arthritis//Ann Rheum Dis, 2018, vol.77, p.A1762.

[3] Papichev E. et al. Fetuin-A: clinical and laboratory associations in women with rheumatoid arthritis//Ann Rheum Dis, 2018, vol.77, p.A1228.

[4] Polyakova J. S. et al. Serum visfatin determination in rheumatoid arthritis // Ann. Rheum. Dis. 2014; 73 (Suppl2).

Disclosure of Interests: None declared

DOI: 10.1136/annrheumdis-2019-eular.1710

\section{FRI0515 HSP90AA1, A CHAPERONE-MEDIATED AUTOPHAGY, IS A BIOMARKER ASSOCIATED WITH DEFECTIVE AUTOPHAGY IN OSTEOARTHRITIS}

Irene Lorenzo ${ }^{1}$, Jose Antonio Pinto Tasende ${ }^{2}$, Natividad Oreiro ${ }^{2}$, Francisco J. Blanco ${ }^{1,2}$, Beatriz Carames ${ }^{1} .{ }^{1}$ Instituto de Investigación Biomédica de A Coruña (INIBIC), Grupo de Investigación en Reumatología, A Coruña, Spain; ${ }^{2}$ Complejo Hospitalario A Coruña, Servicio de Reumatología, A Coruña, Spain

Background: In osteoarthritis (OA), defects in cellular homeostasis, such as autophagy, are evident and precede joint damage (1). We have shown that there is a defect in autophagy in OA human chondrocytes and cartilage (2). Indeed, pharmacological activation of autophagy protects against joint damage (3). Our working hypothesis is that joint damage in OA could be due to a failure of autophagy that can be detected in the blood and tissue of patients.

Objectives: The objective of this study is to identify biomarkers associated with autophagy defects that could facilitate the development of personalized therapeutic strategies to prevent OA progression.

Methods: A comparative analysis of 35 autophagy genes was performed in blood from a Prospective OA Cohort of A Coruña (PROCOAC) of Non-OA and knee OA patients. Non-OA patients (Age: 61,44 \pm 1,16 years; BMl: $25,25 \pm 0,52$; Females, $n=18$ ) and Knee OA patients (Age: $65,50 \pm 1,05$ years; BMI: 29,55 $\pm 0,67$; Females, $n=18$, OA grade III-IV) were profiled using PrimePCR autophagy human panel array (Bio-Rad). Confirmatory studies of the candidate genes were performed in blood from Non-OA patients (Age: 60,13 $\pm 1,12$ years; BMl: $24,85 \pm 0,59$; Females; $\mathrm{n}=30$ ) and Knee-OA patients (Age: $68,4 \pm 1,11$ years; BMI: $29,65 \pm 0,55$; Females; $n=30$, OA grade III-IV) by Taqman Technology. A quantitative proteomic analysis of defective autophagy genes regulated upon deletion of Atg5 in human OA chondrocytes was performed by ITRAQ analysis. Moreover, the candidate gene was evaluated as a potential biomarker in human cartilage from Normal $(n=19)$ and Knee-OA $(\mathrm{n}=20)$ patients and in both spontaneous aging $(6,12,18$, and 30 months old, $\mathrm{n}=3$ ) and surgically-induced $O A$ (10 weeks after surgery, $\mathrm{n}=4$ ) in mice by immunohistochemistry. Remarkably, the consequences of candidate gene silencing on autophagy, FOXO signaling, inflammation, senescence and cell death by apoptosis was investigated by gene expression and flow cytometry.
Results: 15 autophagy-related genes were downregulated in blood from knee OA patients compared to non-OA patients $(p<0.05)$. Importantly, key autophagy-related genes, including ATG16L2, ATG12, ATG4B and MAP1LC3B, involved in relevant process including initiating autophagy, phagophore extension and autophagosome formation, were significan downregulated in knee OA patients $(p<0.05)$. Interestingly, HSP90AA1 and HSPA8, chaperone-mediated autophagy genes involved in stress response and protein folding, were significant downregulated $(p<0.001)$. In addition, several regulators of autophagy and apoptosis, such as BNIP3, BCL-2 and BCL2L1 were downregulated $(p<0.01)$. Confirmatory studies for MAP1LC3B and HSP90AA1, showed a significant downregulation $(p<0.001)$ in blood from knee OA patients. Remarkably, total proteome screening of human $O A$ chondrocytes with defective autophagy, showed a significant reduction of HSP90AA1 $(p<0.05)$. Remarkably, HSP90AA1 expression was reduced in $O A$ cartilage $(p<0.01)$ and in spontaneous aging and surgically-induced $O A$ in mice $(p<0.05)$. Interestingly, HSP90AA1 silencing increased LC3 and FOXO1 expression ( $p>0.01$ ), might be as a protective response, and increased NF $\kappa B$ and $\mathrm{p} 16$ expression $(p<0.05)$ at 48 hours. In addition, genetic deletion of HSP90AA 1 increased cell death by apoptosis $(p<0.05)$. These data indicate that HSP90 might be a potential biomarker associated with defective autoph agy in OA.

Conclusion: We identified biomarkers of defective autophagy as a mecha nism of central homeostasis, which gives us a general vision of the disease mechanisms linked to $O A$ clinical reality.

\section{REFERENCES:}

[1] Lotz MK, Caramés B. Nat Rev Rheumatol. 2011;7:579-87

[2] Caramés B, et al. Arthritis Rheum. 2010;62:791-801.

[3] Caramés B, et al. Ann Rheum Dis. 2012;71:575-81.

Disclosure of Interests: Irene Lorenzo: None declared, Jose Antonio Pinto Tasende: None declared, Natividad Oreiro: None declared, Francisco J. Blanco Consultant for: AbbVie, Bioiberica, BMS, GSK, Grünenthal, Janssen, Lilly, Pfizer, Regeneron, Roche, Sanofi, TRB Chemedica, and UCB, Beatriz Carames: None declared

DOI: 10.1136/annrheumdis-2019-eular.4839

\section{FRI0516 \\ CHONDROGENIC EFFECT OF KARTOGENIN ON AN IMMORTALIZED CELL LINE DERIVED FROM MESENCHYMAL STROMAL CELLS ISOLATED FROM HUMAN BONE MARROW}

Carolina Guiance-Varela ${ }^{1,2}$, Cristina Rodríguez-Pereira ${ }^{1,2}$, Elena FernandezBurguera ${ }^{1,3}$, Tamara Hermida Gómez ${ }^{1}$, Noa Goyanes ${ }^{1}$, Francisco J. Blanco ${ }^{1}$ joana magalhães ${ }^{1,3}{ }^{1}$ Instituto de Investigación Biomédica de A Coruña (INIBIC). CHUAC. SERGAS., Grupo de Investigación en Reumatología (GIR), a coruña, Spain; ${ }^{2}$ Centro de Investigaciones Científicas Avanzadas (CICA). Universidad de A Coruña (UDC)., A Coruña, Spain; ${ }^{3}$ Centro de Investigación Biomédica en Red (CIBER)., Madrid, Spain

Background: Mesenchymal stromal cells (MSCs) currently tested in regenerative medicine approaches for osteoarthritis (OA) present limitations in obtaining stable hyaline-like cartilage phenotype. Kartogenin (KGN) has been recently described to promote both reparative and protective effects hampering the hypertrophic effects of chondrogenesis. ${ }^{1}$

Objectives: The aim of this study is to evaluate the chondrogenic effect of kartogenin on an immortalized cell line (3a6), using a conventional cell pellet model and gold-standard chondroinductor transforming growth factor 3 (TGF-B3), as positive reference.

Methods: $3 a 6$ cells, originally obtained from a 61-year old Asian woman bone marrow, was cultured under pellet culture system with basa (DMEM, low glucose) or commercial chondrogenic medium, supplemented with $10 \mathrm{ng} / \mathrm{ml}$ TGF- $\beta 3$ or $100 \mathrm{nM} \mathrm{KGN}$ for $3,7,14$ and 21 days. Total RNA was isolated and real-time quantitative reverse transcription-polymerase chain reaction (RT-qPCR) was performed, using custom-made primers for runt-related transcription factor 1 (RUNX1), proteoglycan 4 (PRG4), cartilage intermediate layer protein (CILP), collagens type-II (COL2A1), -X (COL10A1) and -I (COL1A1), using RPL13A as housekeeping. Proteogly cans and zonal markers protein synthesis was evaluated by safranin-O (SO) staining and lubricin/PRG4 and CILP immunohistochemical analysis (both 1:500), respectively. The experiment was performed in triplicate and differences judged using one-way ANOVA with Bonferroni's corrections, considering $\mathrm{p}<0.05$ significantly different. 